\title{
Using Word Study Approach to Improve Omani EFL Students' Spelling Performance
}

\author{
Zainab Al-Yahmedi ${ }^{1}$, Saleh Al-Busaidi ${ }^{2} \&$ Fawzia Al-Seyabi ${ }^{2}$ \\ ${ }^{1}$ Ministry of Education, Sultanate of Oman \\ ${ }^{2}$ College of Education, Sultan Qaboos University, Sultanate of Oman \\ Corresponding author: Saleh Al-Busaidi, Sultan Qaboos University, College of Education, PO Box 32, Postal \\ Code 123, Muscat, Sultanate of Oman.
}

Received: June 23, 2019 Accepted: July 24, 2019 Online Published: July 26, 2019

doi: 10.5539/elt.v12n8p112 URL: https://doi.org/10.5539/elt.v12n8p112

\begin{abstract}
The purpose of this study was to investigate the effect of Word Study approach on the development of spelling performance of Grade Five female students in the Sultanate of Oman. The sample of the study consisted of 66 grade five female students from a Governmental Basic Education school in South Al Batinah Governorate. They were divided into two groups: an experimental group who studied spelling using Word Study approach and a control group who studied spelling using the traditional basal approach. The results showed a statistically significant difference between the two groups in favor of the experimental group. The study puts forward some recommendations for future research and for teaching.
\end{abstract}

Keywords: English language teaching, Oman, spelling, word study approach

\section{Introduction}

Spelling is crucial to students' success in reading and writing; this is because word recognition and spelling both rely on similar funds of knowledge. There are many solid research studies that agree that spelling is foundational for reading (Moats, 1984; Reed, 2012) as well as for writing (Kandel \& Perrett, 2015; McCutcheon \& Stull, 2015). Poor spelling can cause dire consequences for struggling learners. Poor spellers are very limited in their ability to communicate, since spelling plays a critical role in reading and writing fluency, as well as in developing capacity within students to become articulate speakers (Gentry, 2001). Students need a level of proficiency in spelling to continue their academic or professional career in the future.

There has been much debate about whether spelling is taught or caught incidentally by children (Peters, 1985) but recent research studies call for explicit spelling instruction (Atkinson, Zhang, Phillips, \& Zeller, 2014). Learners benefit from spelling instruction that is purposeful and follows a gradual model that considers both their developmental stages and different learning styles. Learners move through developmental phases as they learn the sounds, patterns, and structures of the language. Therefore, there is a need for a teaching approach that takes into consideration the developmental stages of children.

Looking through the English language Grade 5 curriculum "English for me" in the Omani public education system, it seems that it supports the assumption that spelling is caught. There is very scant attention paid to spelling. According to the revised version of Grade 5 Curriculum (2017-2018) students learn spelling through the "look, Cover, Write and Check" method. The spellings are selected from the first few lessons of each unit but not tested until the end of the unit. This certainly raises doubts because English spelling system is more complex and learners themselves are complex. Young learners need to explore spelling patterns, sounding out words, decoding and creating meaning chunks. However, teachers often fall back on very traditional teaching approaches and activities. Most teachers give students the same list of words to memorize ignoring that there is variation between children in terms of ability and achievement. There is a need for a teaching approach that allows students to be actively involved with word manipulation and learning about word families. There is a need for an interactive approach that is student-centered and engages students in constructing concepts about the way words work away from rote memorization. The present study investigates the effect of using a particular teaching approach, that is the word study approach, in increasing Omani grade five students' spelling performance. 


\section{Literature review}

\subsection{Approaches to Spelling Instruction}

For many years, spelling has been considered a rote memorization process (Schlagal, 2002). The earliest method of spelling instruction required students to memorize numerous words in list form. Words were seen as having little or no logic or pattern to their spelling. New memorization strategies were introduced in the 1930s and the 1940s in order to assist learners in mastering words for the weekly spelling tests (Massengill, 2006). In addition, students were asked to write each error or correction several times for additional practice. The issue of spelling lists has plagued teachers and researchers for years and there were many deficiencies within the "list approach". Research clearly indicates that memorization of lists of "spelling words" does not promote the development of spelling skills (Bloodgood, 1991). Many students who passed the spelling test were not able to transfer the knowledge to their writing. Getting full marks in weekly spelling tests does not necessarily mean the students are good spellers. It may just mean that they are good at memorizing words. Bloodgood (1991) stated that "memory is not a sufficient tool to make spelling meaningful and lasting" (p. 204). Add to that, providing all students with the same list is not proficient. There is a wide variation in the students' spelling ability and achievement level. Another serious limitation of this approach is that students were asked to memorize words without teaching them any strategies to learn these words. Templeton (2003, p. 738) noted, "most classroom teachers may not be explicitly aware of the nature of English spelling and the different types of information that the system represents; nor may they be comfortable with how best to facilitate the development of this knowledge in students".

In the early 1960s most primary school teachers thought that spelling occurred incidentally when students wrote about their interest. Phrases such as "when the need arises", and "association of ideas" appeared (Westwood, 2005). They believed that the ideas the students were trying to convey and the quality of the language was more important than accuracy in spelling especially for young children. It was believed that too much attention to accuracy in young children's work can demotivate them.

Until the 1970s, teachers and psychologists did not pay a great deal of attention to spelling. The English spelling system was viewed as a "capricious and unprincipled system". During the late 1970s, 1980s and early 1990s significant shifts occurred in the general approach to literacy teaching. There was a movement away from skills-based instruction to a more holistic and integrated approach to reading, writing and spelling (Westwood, 2005). In the latter half of the 20th century the focus of spelling instruction shifted from rote memorization in response to the work of Hanna, Hanna, Hodges, and Rudorf (1966). Their first analysis of spelling generalizations led to a surprising amount of consistency in the English orthographical system. Moreover, the findings of a research study conducted by Read (1971) about children's invented spelling changed teachers' perspectives about how children learn to spell. Read (1971) investigated preschoolers' invented spellings and discovered that their attempts were not just random displays of ignorance and confusion. He observed that children do not always learn to spell on the basis of rote memorization. Some young children invent their own spellings of words, analyzing words into smaller units and spelling these units in creative ways. Read's linguistic analysis exposed a window through which teachers could ascertain the children's tacit understanding of English phonology (Read, 1971). Read's study uncovered a systematic, phonetic logic to preschoolers' categorizations of English speech sounds. His insights inspired other researchers to look for similar logic in students' spellings across time and grade levels (Beers \& Henderson, 1977; Gentry, 1981). This led to the conclusion that children have an innate ability to learn a language, and they construct and use knowledge about letter-sound relationships. Moreover, these two studies sparked interest and investigation into many issues related to spelling, to the point that the concept of developmental stage theory became the basis for the conceptual framework of Word Study approach to teaching spelling, along with intervention as needed (Massengill, 2006).

In recent years, the "whole language" or "natural approach" has been the focus of literacy skills teaching in schools. Teachers dealt with spelling in the context where it was presented rather than teaching it as a separate subject by its own. It is believed that studying words in isolation will not help the child transfer and use this knowledge when writing (Westwood, 2005). The underlying belief in the whole language approach is that children can acquire spelling through engaging them in writing activities with regular constructive feedback from the teacher and peers (Peters, 1985). Teachers using this approach believe that spelling can be caught by children through exposing children to different reading and writing tasks. This approach is child-centered. However, research found that it is difficult to implement specially in large classes because it focuses on "individualized instructions". Another point is that children are heterogeneous with diverse needs and it does not make sense to leave them acquire spelling incidentally and in isolation. Learning to spell through incidental learning is a questionable approach for students with special needs (Gentry, 2001; Graham, Harris, \& Loynachan, 1994; Van Hell, Bosman, \& Bartelings, 2003). 
Later on, the developmental or transitional approach emerged focusing on the stages of development of spelling for learners. Henderson's research revealed five distinct stages of spelling development, which are: preliterate phonetic stage, phonetic or letter name stage, within-word pattern stage, syllable juncture stage and derivational constancies stage (Coiner, 1995). The instruction is individualized or grouped by students who are "using or confusing" the same orthographic features (Schlagal, 2002). The classroom instruction is based on assessment and students' needs, not a predetermined scope.

Nowadays, the nature of spelling has been influenced by technology including mobile phones, emails and social networking texts. Young children are using some of these devices for texting in most of their daily literacy practices. As a result of instant messaging, text messaging, and informal spelling used by contemporary students, spelling is becoming more of a concern for educators. For texting and instant messaging purposes, users often misspell or shorten words within the messages, a process which then becomes part of their academic writing (Shaw, Carlson, \& Waxman, 2007). Sweeny (2010) stated most students now rely on the assistance of spell checks and other technological tools as a replacement for acquiring spelling skills of their own. Therefore, it is important to develop a classroom culture where spelling patterns and features are explained and analyzed by students.

Children are using their senses like ears, eyes and hands for spelling. According to the Department of Education and Children's Services (DECS) (2011) in south Australia, learning to spell is a "multi-sensory process" that involves "auditory strategies, visual strategies, kinesthetic strategies and morphemic and etymological strategies" (p. 6). Learners will likely find spelling English words difficult if they rely on a solo strategy, e.g. sounding out. Children learn to spell unfamiliar words in two main ways; by internalizing the orthographic patterns of written words by imitation and by synthesizing their knowledge of letters and letter clusters with how the word is said in an analogy process. The extent to which these ways are influenced by the ability to segment the word into sounds has not been resolved (Goswami \& Mead, 1992; Moustafa, 1995). Therefore, they need a problem-solving approach like where they can apply their knowledge about words and the spelling system of the English language. There emerged a need for an approach where students can learn through trial and error, modeling, testing hypotheses, receiving feedback and refining their hypotheses and opportunities to practice and play with words. This is where the "Word Study" approach came into play.

\subsection{Word Study Approach}

Word Study is a "student-centered approach to phonics, spelling and vocabulary instruction that actively engages the learners in constructing concepts about the way words work" (Ganske, 2006, p. 1). It has evolved from three decades of research in developmental aspects of word knowledge with children and adults (Henderson, 1990, Henderson \& Beers, 1980, Radke, 2011; Templeton \& Bear, 1992). Word Study approach to teaching phonics, spelling and vocabulary focuses on the orthography of written words in the English language, which comprises three inextricably woven layers: alphabet (letter-sound correspondence), pattern (letter groupings) and meaning (groups of letters or morphemes denoting meaning). Each layer increases in complexity and builds on previous levels (Henderson \& Beers, 1980). Different literacy experts define Word Study differently, but there are enough commonalities among these definitions. Zutell (1992) defines Word Study program as "a cohesive approach that addresses word recognition, vocabulary, and phonics as well as spelling". Elliot and Rietschel (1999) view Word Study as "an organized instructional program for phonics, vocabulary and spelling at the developmental level" (p. 3). Word Study focuses on supporting students' abilities to understand patterns in words and decode words based on letter-sound correspondence. In addition to sounding out words, Word Study also involves associating the pronunciation of words with the meaning of the word (Hoover \& Gough, 1990). According to Williams et al. (2009) Word Study is "an approach to spelling instruction that moves away from focus on memorization" (p. 570). Thus, in Word Study children learn to apply their knowledge to a greater number of words than they could learn by memorization. They do not just learn words, they learn about words. At last, it is a respected spelling approach that has been used widely in teaching children and adults for more than a decade, and it is based on a developmental philosophy that learners' spelling progresses through predictable stages over time (Massengill, 2006).

\subsection{Word Study Activities}

Activities and strategies taught within Word Study programs are designed to focus on the various linguistic properties of words including: phonemic awareness, orthographic knowledge, storage of mental orthographic images, semantic knowledge and morphological awareness (Masterson \& Apel, 2007). Rather than simply writing words many times, students need to be involved in activities that examine words from different perspectives. Examples of these activities are word sorts, word hunts, making words and word games (Radke, 
2011)

\subsubsection{Word Sorting}

Word sorting is based on theories such as that "children make consistent, overt judgments of sound similarities" (Read, 1971, p. 17). During Word Study, students are engaged in activities such as comparing and contrasting word features, sorting words based on different features, and learning word parts and meaning (Bear et al., 2008). Word sorts are a powerful means of exploring words. Word sorting activities help students to think critically about words similarities and differences. They also help students to identify patterns within words which lead them to make generalizations about words and related patterns. According to Zutell (1998) word sorting activities provide instructors with a framework for more individualized instruction at students' developmental spelling levels. Word sorting works well with special needs students. Studies indicate that word sorting boost word knowledge, reading and comprehension of children with learning differences and disabilities (Scraper, 2002). Besides, Word sorting helps students recognize the semantic relationship among key concepts (Bear, Invernizzi, Johnston, \& Templeton, 1996). Add to that, word sorting is an excellent method for teaching complex reasoning skills such as classification and deduction.

\subsubsection{Word Hunt}

Research shows that students find Word Study through word hunt to be a positive and enjoyable experience (Elliott, \& Rietschel, 1999). Research studies also showed that using playful teaching makes learning more satisfying, and reading and writing become real, appealing, and authentic. Words hunt teach students to examine words so they can identify consistencies within our written language system (Bear et al., 2004). According to Barger (2006) words hunt are one way to focus spelling study on patterns within words which is typically used within Word Study instruction. Students hunt for other words that follow the same spelling features studied during their words or pictures sort. Words hunt activities help students make the connection between spelling words and reading words.

\subsubsection{Word Walls}

Word walls are bulletin boards that contain a collection of high-frequency or theme-related words and their activities include games that focus on using the word wall to learn sight words (Jasmine \& Schiesl, 2009). The main purpose of a word wall is to help students build sight word recognition so they can recognize them at a glance. In addition, word walls are visuals that help students remember connections between words. Word walls also serve to teach word analysis and to build vocabulary from units of study. Teachers may also use these words to focus on spelling rules. Ehri (2005) commented that word walls help students to retain knowledge of the word, and ultimately read them with automaticity. Word walls also help students to develop their writing. In writing activities, the teacher can direct students to word walls for help while the teacher works with other students.

\subsection{Spelling Studies in Oman}

In the Omani EFL context, most conducted studies were related to common spelling errors among learners and spelling strategies (Al Bulushi \& Al Seyabi, 2016). Most of these studies focused on spelling difficulties at early grades such as grade 4 (Al Yahyai, 2009), grade 5 (Al-Hassan, 2006; Al-Jabri, 2006) and grade 6 (Al-Harrasi, 2012). Added to that, some studies surveyed spelling problems with tertiary students (Emery, 2005; Mahmoud, 2013; Vaddapalli, 2012). It seems that most of these studies did not take into consideration designing a program or applying an approach to overcome spelling problems. There is a dearth of research that investigates the efficacy of current methods of spelling instruction, teachers' perceptions about spelling, and how they currently handle spelling instruction. Vaddapalli (2012) supported the use of code-based approach as well as whole language approach instead of skills-based approach as suggested by Graham (2000). He argued that the "lack of proper spelling instruction at schools and colleges" is one of the reasons behind the spelling difficulties among learners. Al-Hassan (2006) proposed the use of Graph Paper Spelling (GPS) approach. It is based on the visualization of words in order to help students memorize the shapes of the words. This approach is similar to the "Look, Cover, Write, and Check" method to spelling which is implemented nowadays in most Omani schools in grades 3 and 4. It was also introduced to grade 5 curriculum in the academic year 2017/2018. There are no studies that purely dealt with specific spelling approaches for instruction. Research studies are calling for a systematic teaching of spelling as shown in the literature. Al-Jabri (2006) suggests a systematic study of spelling in which learners are explicitly taught the differences between English and Arabic spelling system. Schonell (1985) commented that spelling should be taught like any other subject and teachers should adopt a suitable and flexible teaching method that is appropriate to students' age, ability and needs. The present study was designed to fill gaps in our knowledge about spelling instruction, especially in the Omani EFL context. 


\section{Method}

\subsection{Research Design}

This study followed the quasi-experimental design. The research design incorporated the Spelling Inventory which was used to assess students' levels of orthographic knowledge. This inventory was used as a pretest and posttest measure. The pre-test was used to test students' orthographic knowledge in order to place them in the spelling continuum.

\subsection{Participants}

Participants of the study were 66 female students from grade five (10-11 years old). Students were enrolled in a Basic Education school in Al Batinah South Governorate in Wilayat of Al Musanah in the Sultanate of Oman. The students were chosen based on the results of the pre-test and they were divided into two groups, control and experimental, with 33 students each. The experimental group received Word Study instruction while the control group was taught in the conventional way. The researchers used pseudo names to report the results of the study.

\subsection{Instrument}

A spelling inventory test was developed by the researchers. It was used for pre and post testing. It consisted of 26 words taken from Unit Two "Food and Health" in the textbook the students were studying at the time of the experiment. The 26 words represented different patterns from the five stages of orthographic development. The test started with the word bag and progressed to the word vegetables. Each word in the list was read aloud, followed by a sentence containing the word if the meaning was unclear and then the teacher repeated the word once again before moving to the next word.

\subsection{Procedures}

Before the intervention started, the students in both groups were given the Spelling Inventory pretest of 26 words ranging from easy to difficult related to unit two "Food and Health". The purpose of this inventory was to determine what spelling stages the students were in and what spelling features they had and had not mastered at that time (Dew, 2012). At the end of the intervention, the total feature points were also assessed and were compared to the pretest feature points. There was a total of eighty two points that accounted for the twenty-six words. Twenty-six of the total points were given for spelling the word correctly. The remaining fifty-six points were awarded for getting feature points correct. If a student got a word correctly, she received one point. For example, if the word jar spelled as jar, then the student got one point. If the targeted feature was short vowel then the student received one point for correct feature. However, if the focus was on initial letters, then the student received a zero point. In the spelling inventory there were different features for assessments starting with initial consonants ending with bases or roots. For example, there were six words on the assessment that assessed initial consonants. Therefore, there were six feature points possible for each word. To assess beginning consonants, the six words assessed were: bag, jar, tin, nut, tea and cola. These words also gave points for other feature areas such as ending consonants and short or long vowel sounds. The results from the inventory were used to place students into spelling groups according to their developmental stage.

\section{Results}

\subsection{Spelling Inventory Pretest Results}

An independent sample t-test was conducted before the intervention to explore whether there was a statistically significant difference in the mean scores of the two groups. Table 1 displays the raw mean gains, standard deviation and standard error mean for the two groups in the pretest. There was no significant difference between the control group $(\mathrm{M}=2.21, \mathrm{SD}=2.08)$ and the experimental group $(\mathrm{M}=2.85, \mathrm{SD}=2.46 ; \mathrm{t}(64)=1.13, \mathrm{p}=$ 0.26 , two-tailed) in the pretest. The magnitude of the differences in the means (mean differences $=.63,95 \% \mathrm{CI}$ : -.487 to .487 ) was very small (eta squared $=0.01)$.

Table 1. Mean scores for the experimental and control groups in the pretest

\begin{tabular}{lllllll}
\hline & Group & $\mathrm{N}$ & Mean & Std. Derivation & Std. Error Mean & df \\
\hline Pretest & Control & 33 & 2.21 & 2.088 & .363 & 32 \\
& Experimental & 33 & 2.85 & 2.464 & .429 & 32 \\
\hline
\end{tabular}

Scoring of the test began with the Emergent stage which is the earliest spelling stage. The first feature assessed 
was beginning consonants. A student needs to get six or five features right out of six features in order to master that feature. If the student missed two or three features this means that she did not master it and instruction should start from there. The results from the inventory showed that all the students in the class were in the Letter-Name stage and Within Word Stage. Within these stages students scored at different levels which are: early, middle and late. Therefore, students were divided among these three levels.

An analysis of the pretest was conducted for the experimental group. The results revealed that students varied in their orthographic knowledge. Their scores ranged from a zero point to 10 points as seen in Figure 1.

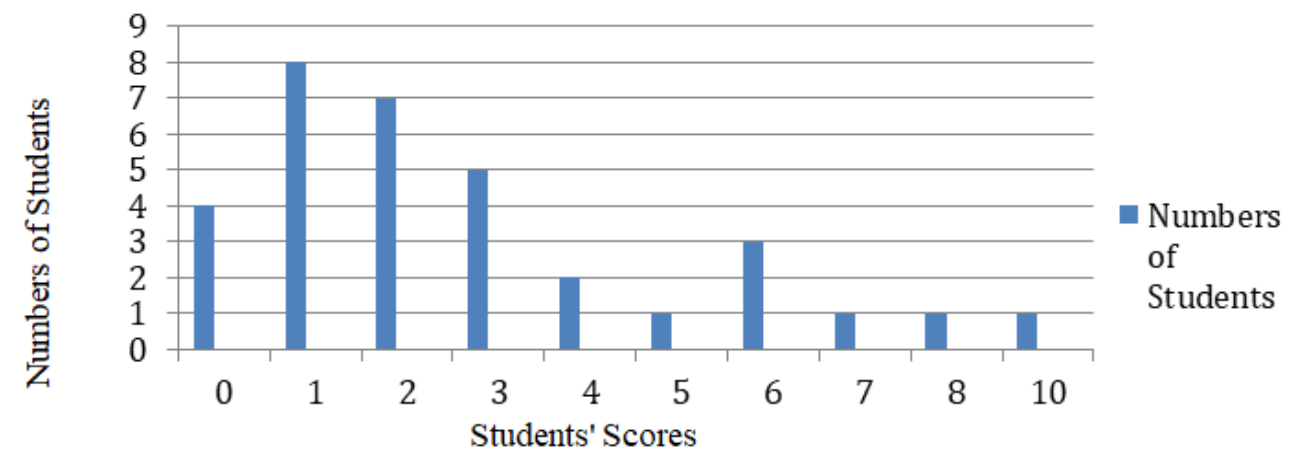

Figure 1. Pretest scores for experimental group

The students were assessed according to the Spelling Inventory in five features which are: initial and final consonants, short and long vowels, consonants blending and digraphs, R- influenced vowels and inflected endings.

Table 2. Distribution of the experimental group among the different stages of spelling development

\begin{tabular}{ll}
\hline Number of Students & Stages of Spelling development \\
\hline 12 & Early Letter-Name \\
12 & Middle Letter -Name \\
3 & Late Letter-Name \\
6 & Early Within Word \\
\hline
\end{tabular}

Table 2 illustrates the distribution of the students in the experimental group among the different stages of spelling development. The analysis of the experimental group test's results revealed that most of the students in the class were in the Letter-Name stage but at different levels: early, middle and late. The first feature assessed was the initial and final consonants. The results showed that 12 students did not master the initial and final consonants. This indicated that these students are in the early letter name-alphabetic spelling stage. Their scores for word spelled correctly were zeroes. These students were referred to as Group A. The next feature assessed was short vowels and the results indicated 12 students did not master this feature. Their scores for word spelled correctly ranged between two to three points. Some of them missed two or three initial and final consonants. This indicated that these students are in the Middle letter name-alphabetic spelling stage. These students were referred to as Group B. The next feature assessed was consonant digraphs and three students missed this feature, which indicated that they did not master this feature. Their scores for word spelled correctly ranged from four to five points. They did well with initial and final consonants as well as with short vowels. Some of them missed one or two short vowels. They also had problems with the next feature "blending" as they made errors. This indicated that these students are in the late letter name-alphabetic spelling stage. These students were referred to as Group C. The remaining students did well in the previous features but they had problems with some complex consonants clusters and long vowels. This indicated that these six students were in the early Within Word stage. Their scores ranged from six to ten points and they were referred to as Group D. Each stage of spelling development deals and focuses on specific word knowledge. Table 3 illustrates the three tiers of orthography and the word knowledge for each level. 
Table 3. Tiers of orthography and word knowledge for each level

\begin{tabular}{|c|c|c|}
\hline Tiers of Orthography & Stages of Spelling Development & Word Knowledge \\
\hline \multirow[b]{2}{*}{ Alphabet } & Emergent & Directionality; letter-sound relationship \\
\hline & Letter Name & $\begin{array}{l}\text { Letter-sound relationship (consonants, } \\
\text { short vowels, consonants blends and } \\
\text { digraphs }\end{array}$ \\
\hline \multirow[t]{2}{*}{ Pattern } & Within Word & $\begin{array}{l}\text { Long vowels, ambiguous vowels, } \\
\text { complex consonants clusters in } \\
\text { one-syllable }\end{array}$ \\
\hline & Syllables and Affixes & $\begin{array}{l}\text { Consonants doublings, prefixes and } \\
\text { suffixes, accented and unaccented } \\
\text { syllables }\end{array}$ \\
\hline Meaning & Derivational Relations & $\begin{array}{l}\text { Spell most words correctly, expand } \\
\text { vocabulary by learning derived Greek } \\
\text { and Latin roots, vowels and consonant } \\
\text { alternations in multisyllabic words }\end{array}$ \\
\hline
\end{tabular}

The analysis of the pretest for the control group was also conducted directly after the test. The results showed that students varied in their orthographic knowledge of the spelling patterns. Their scores ranged between a zero point to eight points. The highest mark in the test was eight and the lowest one was zero as seen in Figure 2 below.

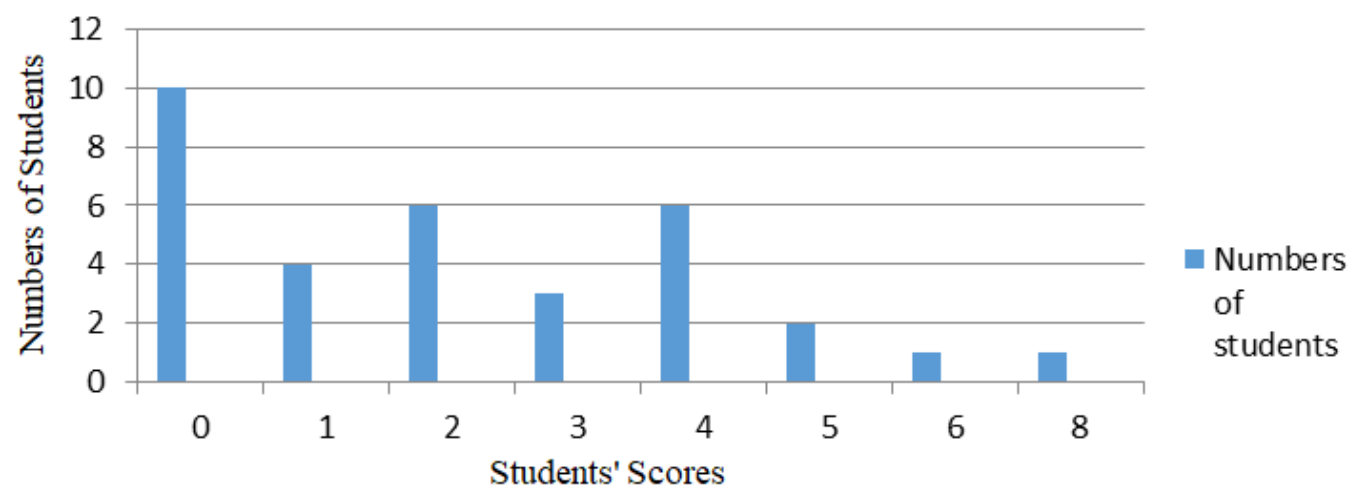

Figure 2. Pretest scores for control group

The results revealed that most of the students are in the Letter-Name stage and two students were in the Within Word stage.

Table 4. Distribution of the control group among the different stages of spelling development

\begin{tabular}{ll}
\hline Number of Students & Stages of Spelling development \\
\hline 14 & Early Letter-Name \\
9 & Middle Letter -Name \\
8 & Late Letter-Name \\
2 & Early Within Word \\
\hline
\end{tabular}

Table 4 illustrates the distribution of the students in the control group among the different stages of spelling 
development. The analysis of the control group test's result showed that around 14 students did not master the initial and final consonants. This indicated that these students are in the early letter name-alphabetic spelling stage (Group A). The next feature was short vowels and 9 students scored between two to three points of word spelled correctly. This indicated that they did not master this feature. They were classified in the middle Letter-Name stage (Group B). Around eight students scored between four to five points in the test. They had problems with digraphs and blending. This indicated that they were in the late Letter-Name stage (Group C). They also had some problems with few short vowels. The last group consisted of two students and they scored between six to eight points. This indicated that they were in the early Within Word stage and they were referred as Group D.

A two-way between-groups analysis of variance was conducted to explore any significant differences between the control and the experimental groups in the pretest. There was no statistically significant difference between the two groups at the $p>.05$ level, $F(1,6.6)=1.28, p=0.26$.

\subsection{Spelling Inventory Posttest results}

At the end of the six weeks of the intervention, the students were given the same Spelling Inventory. The spelling inventory posttest was conducted to explore whether there was a significant difference in students' orthographic knowledge and performance after receiving Word Study instruction for the experimental group. Moreover, it was used to investigate whether there was a significant difference between the experimental group and the control group. When analyzing the student's spelling inventories, three different parts were taken into account: words spelled correctly, feature points, and total points. The analysis of the posttest's results showed a positive increase in the orthographic knowledge of the experimental group. Interestingly, some students showed increase in their knowledge of the consonants, vowels, digraphs and blends as well as R-influenced vowels and inflected endings, which were the focus of the instruction. Unfortunately, some students did not show any growth in their knowledge. The homogeneity of variance test was conducted to test whether the variance in scores is the same for each group. There was no violation of the assumption of homogeneity between groups, $p=0.45$.

\subsection{Independent Sample T-test Results}

An independent sample t-test was conducted for both groups to test if there was any significant difference between the two groups in the posttest. Table 5 illustrates the raw mean gains, standard derivation and the standard error mean for the two groups in the posttest.

Table 5. Pre and posttest means of the control and experimental groups

\begin{tabular}{llll}
\hline & Control group mean & Experimental group mean & Mean change \\
\hline Pretest & 2.21 & 2.85 & .63 \\
Posttest & 5.06 & 8.58 & 3.5 \\
\hline
\end{tabular}

According to the independent sample t-test, there was a statistically significant difference between the control group $(\mathrm{M}=5.06, \mathrm{SD}=4.85)$ and the experimental group $(\mathrm{M}=8.58, \mathrm{SD}=5.28 ; \mathrm{t}(64)=2.8, \mathrm{p}=.006$, two tailed $)$ in the posttest, in favor of the experimental group. The magnitude of the differences in the means (mean differences $=3.5,95 \%$ CI: -1.02 to 1.02 ) was very large (eta squared $=.10$ ). The control group had a positive change of 5.06 in the posttest compared to 2.21 in the pretest. The mean difference between the score was a 2.85 overall change. On the contrary, the experimental group had a positive change from 2.25 in the pretest to 8.58 in the posttest. The mean difference between the scores was a positive 5.73 greater overall change.

\subsection{Paired-sample T-test Results}

A paired-sample t-test was conducted to explore whether there was a significant difference between the total scores of the experimental group in the pretest and posttest. The results showed that there was a significant difference between the two scores in the pretest and posttest for the experimental group, $p<.0005$. There was a statistically significant increase in the spelling inventory scores from the pretest $(\mathrm{M}=2.85, \mathrm{SD}=2.46)$ to the posttest $(\mathrm{M}=8.58, \mathrm{SD}=5.28 ; \mathrm{t}(33)=9.44, p=0.000$ (two-tailed). The mean difference in the two tests' scores was 5.72 with a $95 \%$ confidence interval ranging from 4.49 to 6.96 . The eta squared statistic (.73) indicated a large effect size. This means that there was a great increase in the number of words spelled correctly in the posttest compared to the pretest.

In addition, a paired-sample t-test was carried on to explore any significant difference between the scores of the 
feature points in both tests. The results showed that there was a significant difference between the scores of the feature points in both tests, $p<0.005$. There was a significant increase in the feature points scores for the experimental from the pretest $(\mathrm{M}=21.76, \mathrm{SD}=7.61)$ to the posttest $(\mathrm{M}=28.09, \mathrm{SD}=11.01 ; \mathrm{t}(33)=7.46, \mathrm{p}=$ 0.000 (two-tailed). The mean difference in the two tests' scores was 6.33 with a $95 \%$ confidence interval ranging from 4.60 to 8.06 . The eta squared statistic (.63) indicated a large size effect. These results indicated that Word Study is a significant method of improving students' spelling abilities.

\subsection{The Experimental Group's Results}

The analysis of the test results showed that four students out of 33 students displayed no change in their orthographic knowledge after receiving Word Study instruction.

\subsubsection{Group A Students}

In Group A, there were twelve students in the early level of the Letter-Name Stage according to the pretest results. There was a positive increase in the number of words spelled correctly within this group in the pretest and posttest. One student scored a zero point in both tests and another one scored one point in both tests. The feature points were also calculated for each student in the group. There was an increase in each student's feature points from the pretest to the posttest spelling inventory and it was a slight increase for some students. The analysis of Group A results showed that around ten students from Group A showed a great growth in their knowledge and they moved from the early level to the middle level of the Letter-Name stage. Only two students in Group A did not show any progress in their scores in both tests. This is because these two students were classified as students with learning difficulties. They struggled in school and found reading and writing very difficult. The number of words spelled correctly was the same in the pretest and posttest for both of them. There was an increase in the feature points for both of them but it was a slight increase as well.

\subsubsection{Group B Students}

Group B consisted of twelve students and they were assigned in the middle level of the Letter-Name stage. Contrary to Group A, Group B showed a great growth in the orthographic knowledge. There was a great increase in the number of words spelled correctly, the feature points and the total points in the pretest and posttest. The feature points were calculated for the students in this group. Surprisingly, there was an increase in each student's feature points from the pretest to the posttest. Only three students' scores showed a slight increase in their feature points' scores from the pretest to the posttest. A slight increase refers to a very little increase from one to two points only. The total points for each test were calculated for each student in the group. There was an increase in the total points for each student from the pretest to the posttest. One student showed a decrease from 16 points to 13 points.

The analysis of Group B results revealed that students in Group B showed a positive progress in their scores from the pretest to the posttest. All the 12 students showed a great growth in their orthographic knowledge. Around seven students jumped from middle Letter-Name stage to the next stage, which is the Within Word stage. Around four of them moved to the Syllable and Affixes stage as their scores ranged from eleven to twelve points. However, one student showed a slight increase in her scores in both tests. This was because her confidence level was so low that she needed encouragement and a feeling that she can do it on her own. She also suffered from diabetes, which affected her performance and presence in the class.

\subsubsection{Group C Students}

All Group C students' scores increased after the intervention. All students moved in the continuum from late Letter-Name stage to the early Within Word stage. Moreover, there was an increase in the feature points score for each student in this group. One student showed a decrease of one point in the posttest. The total points were calculated for each student in each test. There was an increase in the total points from the pretest to the posttest except for one student. She had got the same points in the pretest and posttest.

The analysis of Group $\mathrm{C}$ results revealed that Group C students also showed a positive growth in their orthographic knowledge after receiving Word Study instruction. There were three students in this group and two of them showed a great increase in their scores in the posttest. One student moved from the late Letter-Name stage to the Within Word stage and the other one to the Syllable and Affixes stage. The third student showed a slight increase from the pretest to the posttest. This is due to her low self-confidence and attitude towards learning English. She did appear to be apprehensive about sharing aloud and needed encouragement.

\subsubsection{Group D Students}

The last group was Group D and it consisted of six students. All students in this group were classified in the 
early stage of Within Word stage according to the analysis of their scores. All the six students showed a great growth in their orthographic knowledge in both tests. Each of the five students scored high in term of words spelled correctly in both tests.

The feature points were calculated for each student and there was an increase in the number of feature points' scores from the pretest to the posttest. Moreover, there was an increase in the total points for the five students in this group. The analysis of Group D revealed that all of the six students showed a great increase in their orthographic knowledge and they moved in the continuum to the Syllabus Juncture stage. Group D worked well together to sort words and other activities. They communicated their inquiries about words and worked together. They demonstrated proper listening skills with each other.

The results showed that students' orthographic knowledge growth varied among the four groups after receiving Word Study instruction. Students in Group D showed the most significant growth in their orthographic knowledge. Table 7 illustrates the increase in the number of words spelled correctly from the pretest to the posttest for each group in the experimental group.

Table 6. The number of words spelled correctly from the pretest to the posttest for all groups in the experimental group

\begin{tabular}{lll}
\hline Groups & Scores in Pretest & Scores in Posttest \\
\hline Group D & $6-10$ & $16-21$ \\
Group C & $4-5$ & $6-14$ \\
Group B & $2-4$ & $4-12$ \\
Group A & $0-1$ & $2-10$ \\
\hline
\end{tabular}

\subsection{The Control Group Posttest Results}

An analysis of the posttest results was carried on for the control group. This group learned spelling through the traditional way. There was an increase in the number of words spelled correctly in the group compared to the pretest's results. However, some students scored badly in the posttest and they did not show any progress through the unit. Table 8 shows the differences in scores for groups in the control group in the two tests given. The analysis of the control group results showed that there was a growth in the number of the total scores in the posttest compared to the pretest and some students showed no progress at all in both tests. Group D students showed the highest scores, which ranged from 9-18 points in the posttest. The second group in raw was Group C where their scores ranged from 1-14 points in the posttest. The third group was Group A where their scores ranged from 0-9 points in the posttest. The last group was Group B where their scores ranged from 0-8 points in the posttest. Some students showed a slight increase from one to two points.

Table 7. The number of words spelled correctly from the pretest to the posttest for groups in the control Group

\begin{tabular}{lll}
\hline Groups & Scores in Pretest & Scores in Posttest \\
\hline Group D & $6-8$ & $9-18$ \\
Group C & $4-5$ & $1-14$ \\
Group A & $0-1$ & $0-9$ \\
Group B & $2-3$ & $0-8$ \\
\hline
\end{tabular}

\section{Discussion}

The findings of the study indicated that Word Study approach has a positive effect in developing the spelling skills of students. These findings correspond with previous studies about students' orthographic knowledge (Harris, Schumaker, \& Deshler, 2011; Henry, 1987, 2003). Therefore, the current study contributes to the increasing evidence of the impact of Word Study approach in spelling skill. It also serves as a gateway for future examinations of the effects of incorporating this spelling program within the classroom. Further, the results confirm the importance of explicitly teaching spelling patterns to students (Abbott, 2000; Treiman, 1993). The current study reaffirms previous research by focusing on students' deficits and needs. Child development has 
become an important issue not only considering when we should start teaching skills, but also how students should learn those spelling skills (Rabideau, 2016). Students who begin learning from their point of readiness are empowered when they see their improvement rather than discouraged by their inabilities to memorize an arbitrary list of spelling words (Wright, 2003). Previous research studies found that there is a sequence in the acquisition of spelling knowledge which takes place through a series of developmental stages (Gentry,1981, 1997; Ehri, 1987, 2005; Henderson, 1985, 1990; Schlagal, 1992; Bear and Templeton, 1998). Each stage of spelling has been shown to provide important insights into how a learner's spelling develops over time. L1 research on English spelling development shows that spelling skills emerge in stages or phases characterized by an early reliance on phonological codes to map sounds to letters and a later reliance on orthographic and phonological codes that map sounds and spelling patterns to words (Fender, 2008; Ganske, 1999; Morris, 1999). This is important for teachers so that they can apply effective spelling lessons based on students' needs and their developmental stage.

There are some possible reasons why students made a significant progress in their spelling abilities after receiving Word Study instruction. First, Word Study is a developmental approach built on decades of research on children and adults. Each child learns spelling according to his or her level of development. The teacher provides appropriate leveled instruction for each child in order to help them move along the developmental continuum. Moreover, each child has his or her own spelling list according to his or her stage of development. Second, Word Study fits to all different learning styles including visual, auditory, linguistic and kinesthetic. Word Study consists of different hands-on activities which teachers can incorporate into the classroom instruction such as word sorting, words hunt, games and words wall. Third, Word Study is based on social constructivism. Learning occurs through interactions with others. Language is essential for interaction and scaffolding by a more competent peer or adult provides assistance for the learning episodes (Vygotsky, 1986). During Word Study instruction, students are working in groups with similar needs and level of development. The teacher provides support through clues, providing examples and encouraging students. Fourth, Word Study promotes critical thinking skill in a scaffolded environment. During Word Study instruction, students are not told the rule. They have to read the words and inductively think how categories are formed and how spelling patterns differed from each other. They were not told to memorize the rule because teaching is not telling. Fifth, Word Study focuses on both the phonological and orthographic knowledge in relation to reading and spelling. In Word Study instruction students are learning spelling with reading. Words hunt activities focus on the structure and the meaning of the words. It directs students' attention to spelling pattern and root words. It also helps students learn how words are used in different contexts.

The limited effect of Word Study approach on some students may have resulted from the short duration of the intervention. Therefore, there is a need for a longer instruction time to measure the positive effect of Word Study on student spelling. It may also result from the fact that these students lack motivation towards learning English in general and they need encouragement. Therefore, there is a need to investigate the effect of motivation on learning spelling through Word Study instruction. Moreover, students with learning difficulties did not benefit a lot from the intervention. Their feature points increased after the intervention but the scores remained the same in both tests. Therefore, it is crucial to re-examine the effect of Word Study among learners with learning difficulties to fully understand its practicality with this category as a method of spelling instruction within the classroom.

\section{Conclusion}

Word Study approach is an important approach for teaching children spelling and is one that seems to be quite successful. This study found that student achievement increased more significantly when students were grouped based on their orthographic knowledge and needs compared to the routine of whole class instruction. The findings of this study have also shown that there is an increase in orthographic knowledge and spelling abilities when Word Study was used. Future research studies are strongly recommended since not sufficient data had been collected to further differentiate between Word Study and a traditional spelling approach. This study lasted for five weeks with 33 grade five female students. The duration of the intervention was not enough for students, specially the weak ones to increase their orthographic knowledge. A whole semester is needed to monitor students' achievement more closely and see if those five students who did not make gains in this study would make gains after repeating the routines and fully assimilating the new orthographic knowledge. Moreover, this study could have been more conclusive if it had been conducted with a larger sample. Therefore, more future research should be conducted over a longer period of time and with a larger sample size in order to validate the findings. 


\section{References}

Abbott, M. (2000). Reliable spelling rules within orthographic structures. Elementary School Journal, 101(2), 233-245. https://doi.org/10.1086/499666

Al Bulushi, M., \& Al Seyabi, F. (2016). Spelling Strategies of Omani EFL Students. English Linguistics Research, 5(3), 1-14. https://doi.org/10.5430/elr.v5n3p1

Al-Hassan, K. (2006). An Alternative approach to teaching spelling in grade 5. Ministry of Education. Sultanate of Oman.

Al-Harrasi, K. (2012). The most common spelling errors among Omani learners. Arab World English Journal, 3(2), 98-116.

Al-Jabri, F. (2006). Common English spelling difficulties of Omani Learners. Ministry of Education. Sultanate of Oman.

Atkinson, T. S., Zhang, G., Phillips, S. F., \& Zeller, N. (2014). Using word study instruction with developmental college students. Journal of Research in Reading, 37(4), 433-448. https://doi.org/10.1111/1467-9817.12015

Barger, J. (2006). Building word consciousness. The Reading Teacher, 60(3), 279-281. https://doi.org/10.1598/ RT.60.3.8

Bear, D., Invernizzi, M., Johnston, F., \& Templeton, S. (1996). Words their way: Word study for phonics, spelling and vocabulary instruction. Upper Saddle River, NJ: Prentice Hall, Inc.

Bear, D. R., Invvernizzi, M., Templeton, S., \& Johnston, F. (2004). Words their Way. Upper Saddle River, NJ: Merrill Prentice Hall.

Bear, D. R., Helman, L., Templeton, S., Invernizzi, M., \& Johnston, F. (2008). Words their way with English learners. Upper Saddle River, NJ: Merrill Prentice Hall.

Bear, D., \& Templeton, S. (1998). Explorations in developmental spelling: Foundations for learning and teaching phonics, spelling, and vocabulary. The Reading Teacher, 52, 222-242.

Beers, J. W., \& Henderson, E. H. (1977). A study of developing orthographic concepts among first grade children. Research in the Teaching of English, 11, 133-148.

Bloodgood, J. (1991). A new approach to spelling instruction in language arts programs. The Elementary School Journal, 92(2), 203-211. https://doi.org/10.1086/461688

Coiner, J. M. (1995). Is word study the best approach to spelling instruction? A study in the effectiveness of word study vs. a traditional approach to spelling instruction (Reports - Research/Technical, No. 143). University of Virginia. (ERIC Document Reproduction Services No. ED 382 939).

Dew, T. (2012). Word study: A look at improving learning and retention of spelling. Retrieved June 22, 2018, from https://files.eric.ed.gov/fulltext/ED535985.pdf

Ehri, L. (1987). Learning to read and spell words. Journal of Reading Behaviour, 1, 5-31. https://doi.org/10.1080/10862968709547585

Ehri, L. (2005). Learning to read words: Theory, findings, and issues. Scientific Studies of Reading, 9(2), 167-188. https://doi.org/10.1207/s1532799xssr0902_4

Elliott, J. \& Reitschel, K. (1999). The effects of word study on students' application of spelling and phonics in their independent writing. (Report No. CS 216 648) Chandler, IN. (ERIC Document Reproduction Service No. ED $429301)$.

Emery, H. (2005). An investigation into the nature and causes of reading and spelling errors made by Arab ESL learners. (Unpublished $\mathrm{PhD}$ thesis, The University of Wales, Cardiff).

Fender, M. (2008). Spelling knowledge and reading development: Insights from Arab ESL Learners. Reading in a Foreign Language, 20(1), 19-42.

Ganske, K. (1999). The developmental spelling analysis: A measure of orthographic knowledge. Educational Assessment, 6(1), 41-70. https://doi.org/10.1207/S15326977EA0601_4

Ganske, K. (2006). Words sorts and more: Sound, pattern, and meaning explorations, K-3. New York: Guilford Publication.

Gentry, J. R. (1981). Learning to spell developmentally. The Reading Teacher, 34(4), 378-381. 
Gentry, J. R. (1997). My kid can't spell: Practical guidelines, tools, and strategies to help your child spell better, read better, and write better. Portsmouth, NH: Heinemann.

Gentry, J. R. (2001). 5 myths about spelling dispelled! What this means about teaching and learning. Instructor, $111(3), 31-33$.

Goswami, U., \& Mead, F. (1992). Onset and awareness and analogies in reading. Reading Research Quarterly, 27(2), 153-162. https://doi.org/10.2307/747684

Graham, S., Harris, K. R., \& Loynachan, C. (1994). The spelling for writing list. Journal of Learning Disabilities, 27(4), 210-214. https://doi.org/10.1177/002221949402700402

Graham, S. (2000). Should the natural learning approach replace spelling instruction? Journal of Educational Psychology, 92(2), 235-247. https://doi.org/10.1037//0022-0663.92.2.235

Hanna, P. R., Hanna, J. S., Hodges, R. E., \& Roudorf, E. H. (1966). Phoneme-grapheme correspondences as cues to spelling improvement. Washington, DC: U.S. Department of Health, Education, and Welfare, Office of Education.

Harris, M. L., Schumaker, J. B., \& Deshler, D. D. (2011). The effects of strategic morphological analysis on the vocabulary performance of secondary students with and without disabilities. Learning Disability Quarterly, 34(1), 17-33. https://doi.org/10.1177/073194871103400102

Henderson, E. H., \& Beers, J. W. (1980). Developmental and cognitive aspects of learning to spell: A reflection of word knowledge. Newark, DE: International Reading Association.

Henderson, E. H. (1985). Teaching spelling. Dallas, TX: Houghton Mifflin.

Henderson, E. H. (1990). Teaching spelling. Boston, MA: Houghton Mifflin.

Henry, M. (1987). Understanding English orthography: Assessment and instruction for decoding and spelling. (Unpublished doctoral dissertation, Stanford University, Palo Alto, CA).

Henry, M. (2003). Unlocking literacy: Effective decoding and spelling instruction. Baltimore, MD: Paul H. Brookes. https://doi.org/10.1046/j.1440-1754.2003.t01-4-00122.x

Hoover, W. A., \& Gough, P. B. (1990). The simple view of reading. Reading and Writing: An Interdisciplinary Journal, 2, 127-160. https://doi.org/10.1007/BF00401799

Jasmine, J., \& Schiesl, P. (2009). The effects of word walls and word wall activities on the reading fluency of first grade students. Reading Horizons, 49(4), 301-314.

Mahmoud, A. (2013). Spelling errors of Arab learners of EFL: A two-way analysis. TESOL Arabia Perspectives, 20(1), 6-12.

Masterson, J., \& Apel, K. (2007). Spelling and word-level reading: A multilinguistic approach. In A. Kamhi, J. Masterson, \& K. Apel (Eds.), Clinical decision making in developmental language disorders (pp. 249-266). Baltimore, MD: Paul H. Brookes Publishing Company.

Massengill, D. (2006). Mission accomplished...it's learnable now: Voices of mature challenged spellers using a word study approach. Journal of Adolescent \& Adult Literacy, 49, 420-431. https://doi.org/10.1598/ JAAL.49.5.6

Grade 5 Curriculum. (2017-2018). Ministry of Education. Sultanate of Oman: Ministry of Education.

Moats, L. (1984). A comparison of the spelling errors of older dyslexic and second-grade normal children. Annals of Dyslexia Journal, 33(1), 121-140. https://doi.org/10.1007/BF02648000

Morris, D. (1999). The Howard Street tutoring manual: Teaching at risk readers in the primary grades. New York: Guilford.

Moustafa, M. (1995). Children's productive phonological recoding. Reading Research Quarterly, 30(3), 464-476. https://doi.org/10.2307/747626

Peters, M. L. (1985). Spelling caught or taught: A New Look. London: Routledge \& Kegan Paul plc.

Rabideau, S. K. (2016). Word study promotes the application of spelling skills within elementary students' independent writing. (Unpublished Master's Thesis, School of Education. Hamline University Saint Paul, Minnesota, USA).

Radke, J. (2011). Does word work really work? Investigating the effects of word work vs. traditional spelling instruction during guided reading (Unpublished master's thesis). Retrieved July 16, 2018, from 
http://minds.wisconsin.edu/handle/1793/55791

Read, C. (1971). Pre-school children's knowledge of English phonology. Harvard Educational Review, 41(1), 1-34. https://doi.org/10.17763/haer.41.1.91367v0h80051573

Reed, D. K. (2012). Why teach spelling? Portsmouth, NH: RMC Research Corporation, Center on Instruction. Retrieved from http://www.centeroninstruction.org/files/Why\%20Teach\%20Spelling.pdf

Schlagal, R. (1992). Patterns of orthographic development into the intermediate grades. In S. Templeton, \& D. Bear (Eds.), Development of orthographic knowledge and the foundation of literacy: A memorial Festschrift for Edmund H. Henderson (pp. 31-52). Hillsdale, NJ: Erlbaum.

Schlagal, B. (2002). Classroom spelling instruction: History, research, and practice. Reading Research and Instruction, 42(1), 44-57. https://doi.org/10.1080/19388070209558380

Schonell, F. J. (1985). Essentials in teaching and testing spelling. London: Macmillan.

Scraper, K. (2002). Word study through sorting. Educators Publishing Service, a division of Deita Education, LLC.

Shaw, D. M., Carlson, C., \& Waxman, M. (2007). An exploratory investigation into the relationship between text messaging and spelling. The New England Reading Association Journal, 43, 57-62.

Sweeny, S. M., (2010). Writing for the instant messaging and text messaging generation: Using new literacies to support writing instruction. Journal of Adolescent \& Adult Literacy, 54, 121-130. https://doi.org/ 10.1598/JAAL.54.2.4

Templeton, S. (2003). Spelling. In J. Flood, D. Lapp, J. R. Squire, \& J. M. Jensen (Eds.), Handbook of research on teaching the English language arts (2nd ed., pp. 738-751). Mahwah, New Jersey: Erlbaum.

Templeton, S., \& Bear, D. (1992). Development of orthographic knowledge and the foundation of literacy: A memorial Festschrift for Edmund H. Henderson. Hillsdale, NJ: Erlbaum.

Treiman, R. (1993). Beginning to spell. New York: Oxford University Press.

Van Hell, J. G., Bosman, A.T., \& Bartelings, M. G. (2003). Visual dictation improves the spelling performance of three groups of Dutch students with spelling disabilities. Learning Disability Quarterly, 26(4), 239-255. https://doi.org/10.2307/1593637

Vaddapalli, M. (2012). Spelling and Auditory Discrimination difficulties of students in Oman: An analysis. Language in India, 12(1), 261-276.

Vygotsky, L. S. (1986). Thought and language. Cambridge, MA: MIT Press.

Westwood, P. (2005). Spelling: Approaches to teaching and assessment (2nd ed.). Melbourne: Australian Council for Educational Research.

Williams, C., Philips-Birdson, C., Hufnagel, K., Hungler, D., \& Lundstrom, R. P. (2009).Word study instruction in the K-2 classroom. The Reading Teacher, 62(7), 570-578. https://doi.org/10.1598/RT.62.7.3

Wright, J. (2003). The effects of word study: A developmental and discovery based approach to spelling. (Unpublished master's thesis, Rowan University, New Jersey, USA).

Zutell, J. (1992). An integrated view of word knowledge: Correlational studies of the relationships among spelling, reading, and conceptual development. In S. Templeton, \& D. R. Bear (Eds.). Development of orthographic knowledge and the foundation of literacy: A memorial Festschrift for Edmund H. Henderson (pp. 213-230). Hillsdale, NJ: Erlbaum.

Zutell, J. (1998). Word sorting: A developmental spelling approach to word study for delayed readers. Reading \& Writing Quarterly, 14(2), 219-238. https://doi.org/10.1080/1057356980140205

\section{Copyrights}

Copyright for this article is retained by the author(s), with first publication rights granted to the journal.

This is an open-access article distributed under the terms and conditions of the Creative Commons Attribution license (http://creativecommons.org/licenses/by/4.0/). 